\title{
Aberrant Light-Induced Depression is Associated with Impaired Sensorimotor Gating in Mice
}

\author{
Toshiaki Haga1,2, Junichi Toei1', Kenichi Mitsui' ${ }^{1}$, Mareki Ohtsuji', \\ Yo Kodera1, Kenichi Osada ${ }^{2}$, Hiroyuki Nishimura1 ${ }^{1}$ \\ ${ }^{1}$ Department of Biomedical Engineering, Toin University of Yokohama, Yokohama, Japan \\ ${ }^{2}$ Department of Neuropsychiatry, St. Marianna University School of Medicin, Kawasaki, Japan \\ Email: t-haga@marianna-u.ac.jp, jtoei@toin.ac.jp, mitsui@toin.ac.jp, mareki@toin.ac.jp, kodera@toin.ac.jp, \\ k2osada@marianna-u.ac.jp, nisimura@toin.ac.jp
}

How to cite this paper: Haga, T., Toei, J., Mitsui, K., Ohtsuji, M., Kodera, Y., Osada, K. and Nishimura, H. (2018) Aberrant Light-Induced Depression is Associated with Impaired Sensorimotor Gating in Mice. World Journal of Neuroscience, $\mathbf{8}$, $1-9$.

https://doi.org/10.4236/wjns.2018.81001

Received: November 24, 2017

Accepted: December 12, 2017

Published: December 15, 2017

Copyright $\odot 2018$ by authors and Scientific Research Publishing Inc. This work is licensed under the Creative Commons Attribution International License (CC BY 4.0).

http://creativecommons.org/licenses/by/4.0/

\begin{abstract}
Mice subjected to an irregular light-dark cycle are known to lose their capacity to synchronize their behavioral rhythm to environmental light, and to show endophenotypes related to depressive disorders. Here we observed that a susceptible strain of mice $(\mathrm{C} 3 \mathrm{H} / \mathrm{HeJ})$ subjected to an irregular $3.5 \mathrm{hr}: 3.5 \mathrm{hr}$ light-dark cycle showed an enhanced acoustic startle reflex and deficits in prepulse inhibition. As impaired sensorimotor gating is associated with the onset of a variety of mental disorders such as schizophrenia and major depressive disorder, irregular environmental light without circadian photo-entrainment may cause stress that has the potential to be involved in humans' susceptibility to neuropsychiatric abnormalities.
\end{abstract}

\section{Keywords}

Depression, Sensorimotor Gating, C3H/HeJ, Prepulse Inhibition, Circadian Rhythm

\section{Introduction}

Sleep disorders are commonly associated with prevalent neuropsychiatric disorders such as mood disorders and anxiety disorders [1]. It is speculated that etiological factors responsible for mental disorders are also in conflict with the circadian and homeostatic regulation of sleep-wake cycles [2]. However, the possible cause-effect relationship and the exact mechanisms underlying the link between disturbed sleep-wake cycles and mental disorders are unknown. Rodent 
models of neuropsychiatric disorders have provided insights into the nature of the stressors interacting with sleep-wake rhythms. LeGates et al. [3] reported that mice subjected to an ultradian cycle consisting of $3.5 \mathrm{hr}$ of light and $3.5 \mathrm{hr}$ of dark (T7) lost their circadian photo-entrainment capacity and showed a rhythm of activity governed by the central biological clock in the suprachiasmatic nuclei (SCN) [4]. These mice showed depression-like behaviors and learning disability [3]. In the present study, we observed that in a susceptible strain of mice, the same environmental conditions caused impaired sensorimotor gating.

\section{Materials and Methods}

\subsection{Animals}

All procedures were conducted following U.S. National Institutes of Health (NIH) guidelines [5] and were approved by the Animal Experiment Committee at Toin University of Yokohama. Male C3H/HeJ and C57BL/6N mice (12 weeks old) were obtained from Sankyo Laboratory (Shizuoka, Japan) and maintained in the animal facility at the university.

\subsection{Experimental Procedure}

The mice were housed individually in light-controlled housing equipped with an infrared sensor for activity monitoring (Mm Monitoring System ver. 2.0, System Biotics, Kanagawa, Japan). Food and water were offered ad libitum. Two groups of mice $(\mathrm{n}=4)$ for each strain were initially entrained to a $12 \mathrm{hr}: 12 \mathrm{hr}$ light-dark cycle (T24), after which one group was switched to a $3.5 \mathrm{hr}: 3.5 \mathrm{hr}$ light-dark cycle (T7) for another 2 weeks. The other control group remained in the T24 cycle. The light intensity during the light period was $800 \mathrm{~lx}$. Activity monitoring was conducted with Mouse Pathfinder software ver. 3.0 (System Biotics). A sucrose-preference test was conducted as described [6] using two bottles, one containing water and the other containing water with varying concentrations of sucrose (Nacalai Tesque Inc, Kyoto, Japan).

\subsection{Prepulse Inhibition (PPI) of Acoustic Startle Reflex}

We measured the prepulse inhibition (PPI) of the acoustic startle response using an SR-LAB system (San Diego Instruments, San Diego, CA) as described [7]. The sound-attenuating chambers of this system are equipped with a cylindrical acryl glass animal enclosure and a small electric fan which generates a 65-dB background noise and provides ventilation. Broadband sound pulses are presented via a speaker positioned directly above the animal. An accelerometer affixed to the animal enclosure's frame detects the transduced motion resulting from the animal's startle response (whole body flinch). Sound pulse parameters are controlled using SR-LAB software, which also records the startle response.

For the measurement of the PPI, each animal was acclimated to the enclosure for 5 min before being tested during 32 discrete trials. In the first two trials, the 
magnitude of the startle response evoked by a 120 -dB sound pulse (30-msec duration) was measured. These first two startling pulses were presented to habituate the animals to the testing procedure and were omitted from the data analysis. In the subsequent 30 trials, the startle pulse was either presented alone or at $100 \mathrm{msec}$ after the presentation of $30-\mathrm{msec}$ prepulses with intensities 6, 9, 12, and $15 \mathrm{~dB}$ above the background noise. Each prepulse was presented five times and varied randomly among the trials. The animals were subjected to the startle pulse alone during the other 10 trials spaced randomly. The average intertrial interval was $15 \mathrm{sec}$ (range 5 - $30 \mathrm{sec}$ ). The percent PPI was calculated as $100-$ [(startle response to the prepulse followed by the pulse trial/startle response to the pulse-alone trials) $\times 100]$.

\subsection{Statistical Analysis}

All statistical analyses were performed using GraphPad Prism ver. 5 (GraphPad Software, La Jolla, CA).

\section{Results}

\subsection{The Effect of the Aberrant Light-Dark Cycle on the Circadian Rhythm of General Activity}

Figure 1 compares actographs of representative $\mathrm{C} 3 \mathrm{H} / \mathrm{HeJ}$ and $\mathrm{C} 57 \mathrm{BL} / 6$ mice. In the T24 (normal) cycle, the $\mathrm{C} 3 \mathrm{H} / \mathrm{HeJ}$ mice showed activity strictly controlled by the daily light-dark cycle, i.e., being active during the dark period and inactive

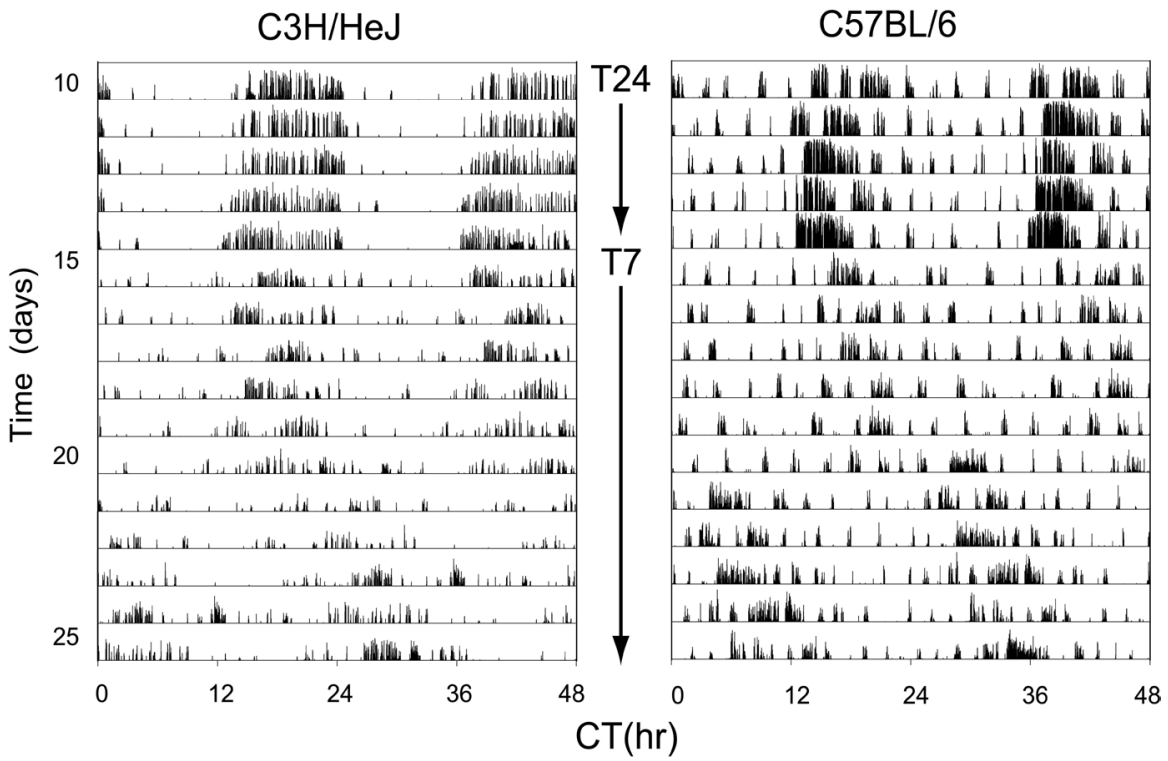

Figure 1. Comparison of the general activity rhythms of $\mathrm{C} 3 \mathrm{H} / \mathrm{HeJ}$ and $\mathrm{C} 57 \mathrm{BL} / 6$ male mice (12 wks old). Representative actograms for each single mouse housed individually with an infrared sensor for activity monitoring are shown. In each row, the cumulative event-counts in $1 \mathrm{~min}$ are shown by the vertical bar graphs, and clock time over the period of 48 hours is shown on the horizontal axis. Actograms from day 10 to day 14 (T24 cycle) and those from day 15 to day 25 (T7 cycle) are shown consecutively from top to bottom. 


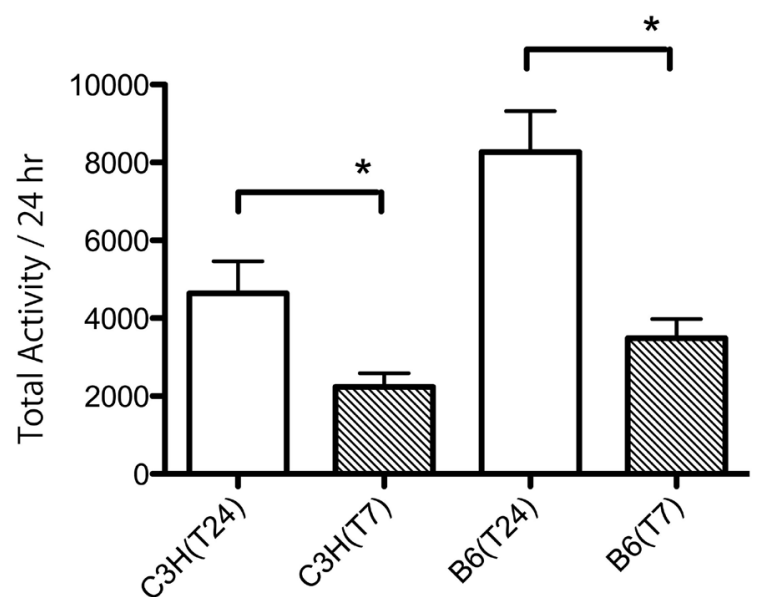

Figure 2. Reduction of the general activities of $\mathrm{C} 3 \mathrm{H} / \mathrm{HeJ}$ and $\mathrm{C} 57 \mathrm{BL} / 6$ mice in the aberrant $3.5 \mathrm{hr}: 3.5 \mathrm{hr}$ light-dark cycle (T7). Average cumulative event-counts per hr on day 11 (T24 cycle) and day 21 (T7 cycle) for groups of mice $(n=4)$ were compared by paired Student's t-test $\left({ }^{*} p<0.05\right)$. Error bars indicate SEM.

during the light period. In contrast, the C57BL/6 mice under the normal T24 cycle showed a less stringent pattern, being occasionally active even during the light period. These characteristics of the actographs of the two strains of mice are in keeping with a previous report [8].

When subjected to the aberrant T7 cycle, both strains of mice lost the rhythmic pattern of activities temporarily, and then gradually began to show rhythms governed by their own central circadian pacemaker showing the gradual shifts of active periods. There was also a gradual decline of total activity as detected by the infrared sensors in both strains of mice under the T7 cycle (Figure 2). These mice showed significant reductions of sucrose preference (anhedonia), which is an endophenotype associated with human depressive disorder (data not shown).

\subsection{Enhanced Startle Reflex and Deficits in PPI in the C3H/HeJ Mice}

As shown in Figure 3(a), after being subjected to the T7 cycle, the $\mathrm{C} 3 \mathrm{H} / \mathrm{HeJ}$ mice showed a significant enhancement of the magnitude of the startle response, a phenomenon which is known to be associated with anxiety disorder [9]. These mice also showed reduced PPI as evidenced by the average startle responses after three of the four levels of prepulses tested (Figure 3(b)). In C57BL/6 mice, there was no significant enhancement of the magnitude of startle reflex or a reduction of PPI.

\section{Discussion}

In mice as well as in humans, the circadian rhythm of general activity is governed by the central circadian pacemaker that is operated by the neurons in the suprachiasmatic nucleus (SCN) [10]. The rhythmic oscillation of clock gene expressions is adjusted and synchronized to the daily light-dark cycle [11]. Melanopsin-expressing intrinsically photosensitive neurons in the retina are 


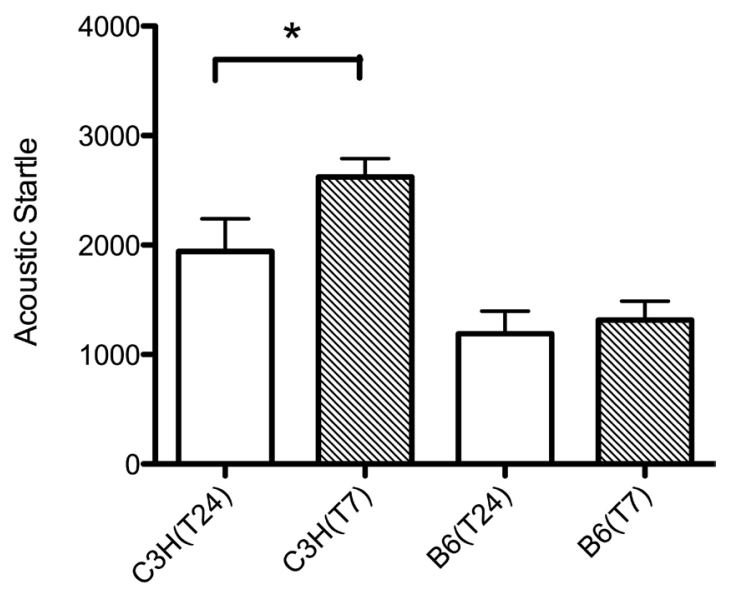

(a)

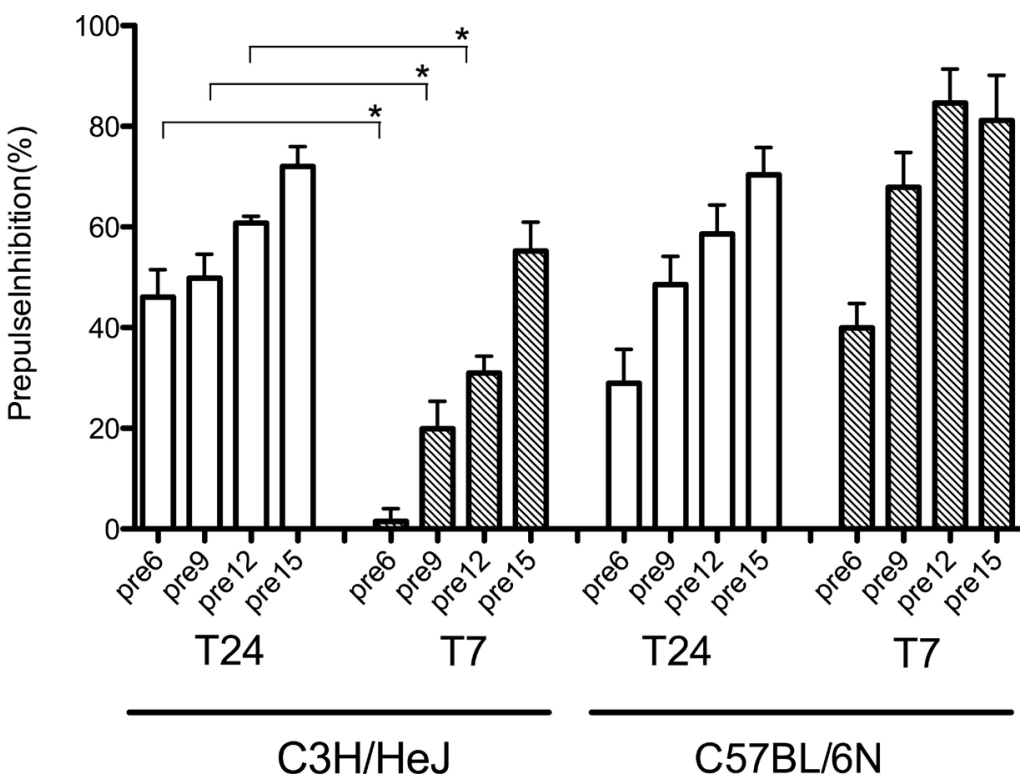

(b)

Figure 3. Tests for acoustic startle response and prepulse inhibition were conducted as described in Material and Methods. (a) Enhanced startle response in $\mathrm{C} 3 \mathrm{H} / \mathrm{HeJ}$ mice ( $\mathrm{n}=$ 4) subjected to the aberrant $3.5 \mathrm{hr}: 3.5 \mathrm{hr}$ light-dark cycle (T7). The difference in the average response in the T24 and T7 cycles by 120 -dB-pulse stimuli without prepulse was tested by Student's t-test. (b) Reduced prepulse inhibition (PPI) observed in C3H/HeJ mice $(n=4)$ subjected to the T7 cycle. Average levels of responses were compared by Student's t-test. ${ }^{\star} p<0.05$. Error bars indicate SEM. Reduced PPI of $\mathrm{C} 3 \mathrm{H} / \mathrm{HeJ}$ mice in T7 cycle was confirmed by two independent experiments.

known to be responsible for this adjustment [12]. Failure in this entraining disturbs the cognitive functions and causes mood disorders [11].

LeGates et al. reported that mice subjected to a T7 cycle lost their circadian photo-entrainment and showed depression-like phenotypes. However, those authors observed that mice lacking intrinsically photosensitive retinal ganglion cells (ipRGCs) did not show such phenotypes under the T7 cycle, and they concluded that ipRGCs were responsible for the transduction of stress signal [3]. Melanopsin-containing ipRGCs are sensitive to short-wavelength (blue) light 
and are known to be responsible for the entrainment of circadian cycles [13]. In the present study, we observed that the same aberrant light cycle disrupted the normal function of sensorimotor gating as measured by the PPI of the acoustic startle response.

The PPI of the startle response is widely used as a measure of the function of sensorimotor gating. The acoustic startle reflex is mediated by brainstem nuclei such as the nucleus reticularis pontis caudalis in the brainstem [14]. However, this startle response is regulated by more rostral structures, including the temporal and medial prefrontal cortex, the ventral striatum, the ventral pallidum, and the pontine tegmentum [15] [16]. Impaired PPI has been described in schizophrenia [17], Tourette syndrome [18], obsessive compulsive disorder (OCD) [19], and in mood disorders [20]. Various gene-targeted mice have been tested for PPI as a quantitative measure of sensorimotor gating, the deficit of which is likely involved in the etiological bases of neuropsychiatric disorders.

Reduced PPI was reported for mice deficient in Disc1 [21] [22], Reln [23], Nrg1 [24] [25], Gnaq [26], Smarca2 [27], Nrxn1 [28], and Akt1 [29] genes, which have been shown to be linked to the susceptibility to schizophrenia in human genetic studies. Mice deficient in genes coding for various neurotransmitters, neuropeptides, and orphan receptors possibly involved in neuronal functions were also tested for the deficit of PPI (reviewed by Powell et al. [30]). Of particular interest among these studies was that the environmental factors were also involved in the PPI. Mice with the transcription factor Nurr1-null heterozygous genotype $(+/-)$, which have lower levels of dopamine in the whole brain, showed reduced PPI after postnatal early isolation rearing, an effect that was not observed with normal in-group rearing [31]. That study provided experimental evidence that environmental stress contributed to susceptibility to impaired sensorimotor gating.

\section{Conclusion}

In the present study, we demonstrated that environmental stress alone as induced by irregular light in the context of the sleep-wake cycle caused impaired PPI in the susceptible strain of mice. Our present observations suggest that irregular environmental light without circadian photo-entrainment is likely to be involved in the susceptibility to various types of neuropsychiatric disorders.

\section{References}

[1] Kupfer, D.J., Peel, R., Reynolds III, C.F., Sateia, M., Buysse, D. and Thorpy, M. (2000) Sleep Disorders. In: Frances, A.P.H.A., First, M.B., et al., Eds., Diagnostic and Statistical Manual of Mental Disorders (DSV-IV-TR), Fourth Edition, American Psychiatric Association, Washington DC, 597-662.

[2] Borbely, A.A. and Achermann, P. (1992) Concepts and Models of Sleep Regulation: An Overview. Journal of Sleep Research, 1, 63-79.

https://doi.org/10.1111/j.1365-2869.1992.tb00013.x

[3] LeGates, T.A., Altimus, C.M., Wang, H., Lee, H.K., Yang, S., Zhao, H., Kirkwood, 
A., Weber, E.T. and Hattar, S. (2012) Aberrant Light Directly Impairs Mood and Learning through Melanopsin-Expressing Neurons. Nature, 491, 594-598. https://doi.org/10.1038/nature11673

[4] Altimus, C.M., Guler, A.D., Villa, K.L., McNeill, D.S., Legates, T.A. and Hattar, S. (2008) Rods-Cones and Melanopsin Detect Light and Dark to Modulate Sleep Independent of Image Formation. Proceedings of the National Academy of Sciences of the United States of America, 105, 19998-20003.

https://doi.org/10.1073/pnas.0808312105

[5] Garber, J.C., Barbee, R.W., Bielitzki, J.T., Clayton, L.A., Donovan, J.C., Kohn, D.F., Lipman, N.S., Locke, P.A., Melcher, J., Quimby, F.W., Patricia, V.T., Wood, G.A. and Wurbel, H. (2011) Guide for the Care and Use of Laboratory Animals, Eighth ed., The National Academies Press, Washington, D. C.

[6] Katz, R.J. (1982) Animal Model of Depression: Pharmacological Sensitivity of a Hedonic Deficit. Pharmacology Biochemistry and Behavior, 16, 965-968.

https://doi.org/10.1016/0091-3057(82)90053-3

[7] Geyer, M.A. and Swerdlow, N.R. (2001) Measurement of Startle Response, Prepulse Inhibition and Habituation. Current Protocols in Neuroscience, Chapter 8, Unit 8.7. https://doi.org/10.1002/0471142301.ns0807s03

[8] Tankersley, C.G., Irizarry, R., Flanders, S. and Rabold, R. (2002) Circadian Rhythm Variation in Activity, Body Temperature and Heart Rate between $\mathrm{C} 3 \mathrm{H} / \mathrm{HeJ}$ and C57BL/6J Inbred Strains. Journal of Applied Physiology (1985), 92, 870-877. https://doi.org/10.1152/japplphysiol.00904.2001

[9] Nelson, B.D., Hodges, A., Hajcak, G. and Shankman, S.A. (2015) Anxiety Sensitivity and the Anticipation of Predictable and Unpredictable Threat: Evidence from the Startle Response and Event-Related Potentials. Journal of Anxiety Disorders, 33, 62-71. https://doi.org/10.1016/j.janxdis.2015.05.003

[10] Gillette, M.U. and Mitchell, J.W. (2002) Signaling in the Suprachiasmatic Nucleus: Selectively Responsive and Integrative. Cell and Tissue Research, 309, 99-107. https://doi.org/10.1007/s00441-002-0576-1

[11] Foster, R.G. and Wulff, K. (2005) The Rhythm of Rest and Excess. Nature Reviews of Neuroscience, 6, 407-414. https://doi.org/10.1038/nrn1670

[12] Hattar, S., Liao, H.W., Takao, M., Berson, D.M. and Yau, K.W. (2002) Melanopsin-Containing Retinal Ganglion Cells: Architecture, Projections and Intrinsic Photosensitivity. Science, 295, 1065-1070. https://doi.org/10.1126/science.1069609

[13] Berson, D.M., Dunn, F.A., and Takao, M. (2002) Phototransduction by Retinal Ganglion Cells That Set the Circadian Clock. Science, 295, 1070-1073.

https://doi.org/10.1126/science.1067262

[14] Davis, M., Gendelman, D.S., Tischler, M.D., and Gendelman, P.M. (1982) A Primary Acoustic Startle Circuit: Lesion and Stimulation Studies. Journal of Neuroscience, 2, 791-805.

[15] Arai, S., Takuma, K., Mizoguchi, H., Ibi, D., Nagai, T., Takahashi, K., Kamei, H., Nabeshima, T., and Yamada, K. (2008) Involvement of Pallidotegmental Neurons in Methamphetamine- and Mk-801-Induced Impairment of Prepulse Inhibition of the Acoustic Startle Reflex in Mice: Reversal by Gabab Receptor Agonist Baclofen. Neuropsychopharmacology, 33, 3164-3175. https://doi.org/10.1038/npp.2008.41

[16] Koch, M. and Bubser, M. (1994) Deficient Sensorimotor Gating after 6-Hydroxydopamine Lesion of the Rat Medial Prefrontal Cortex Is Reversed by Haloperidol. European Journal of Neuroscience, 6, 1837-1845. https://doi.org/10.1111/j.1460-9568.1994.tb00576.x 
[17] Braff, D., Stone, C., Callaway, E., Geyer, M., Glick, I. and Bali, L. (1978) Prestimulus Effects on Human Startle Reflex in Normals and Schizophrenics. Psychophysiology, 15, 339-343. https://doi.org/10.1111/j.1469-8986.1978.tb01390.x

[18] Smith, S.J. and Lees, A.J. (1989) Abnormalities of the Blink Reflex in Gilles De La Tourette Syndrome. Journal of Neurology, Neurosurgery, and Psychiatry, 52, 895-898. https://doi.org/10.1136/jnnp.52.7.895

[19] Swerdlow, N.R., Benbow, C.H., Zisook, S., Geyer, M.A. and Braff, D.L. (1993) A Preliminary Assessment of Sensorimotor Gating in Patients with Obsessive Compulsive Disorder. Biological Psychiatry, 33, 298-301.

https://doi.org/10.1016/0006-3223(93)90300-3

[20] Perry, W., Minassian, A. and Feifel, D. (2004) Prepulse Inhibition in Patients with Non-Psychotic Major Depressive Disorder. Journal of Affective Disorders, 81, 179-184. https://doi.org/10.1016/S0165-0327(03)00157-5

[21] Hikida, T., Jaaro-Peled, H., Seshadri, S., Oishi, K., Hookway, C., Kong, S., Wu, D., Xue, R., Andrade, M., Tankou, S., Mori, S., Gallagher, M., Ishizuka, K., Pletnikov, M., Kida, S. and Sawa, A. (2007) Dominant-Negative Disc1 Transgenic Mice Display Schizophrenia-Associated Phenotypes Detected by Measures Translatable to Humans. Proceedings of the National Academy of Sciences of the United States of America, 104, 14501-14506. https://doi.org/10.1073/pnas.0704774104

[22] Lipina, T.V., Kaidanovich-Beilin, O., Patel, S., Wang, M., Clapcote, S.J., Liu, F., Woodgett, J.R. and Roder, J.C. (2011) Genetic and Pharmacological Evidence for Schizophrenia-Related Disc1 Interaction with Gsk-3. Synapse, 65, 234-248. https://doi.org/10.1002/syn.20839

[23] Barr, A.M., Fish, K.N., Markou, A. and Honer, W.G. (2008) Heterozygous Reeler Mice Exhibit Alterations in Sensorimotor Gating but Not Presynaptic Proteins. European Journal of Neuroscience, 27, 2568-2574. https://doi.org/10.1111/j.1460-9568.2008.06233.x

[24] Chen, Y.J., Johnson, M.A., Lieberman, M.D., Goodchild, R.E., Schobel, S., Lewandowski, N., Rosoklija, G., Liu, R.C., Gingrich, J.A., Small, S., Moore, H., Dwork, A.J., Talmage, D.A. and Role, L.W. (2008) Type Iii Neuregulin-1 Is Required for Normal Sensorimotor Gating, Memory-Related Behaviors, and Corticostriatal Circuit Components. Journal of Neuroscience, 28, 6872-6883.

https://doi.org/10.1523/JNEUROSCI.1815-08.2008

[25] Kato, T., Kasai, A., Mizuno, M., Fengyi, L., Shintani, N., Maeda, S., Yokoyama, M., Ozaki, M. and Nawa, H. (2010) Phenotypic Characterization of Transgenic Mice Over-Expressing Neuregulin-1. PLoS ONE, 5, e14185. https://doi.org/10.1371/journal.pone.0014185

[26] Kelly, M.P., Stein, J.M., Vecsey, C.G., Favilla, C., Yang, X., Bizily, S.F., Esposito, M.F., Wand, G., Kanes, S.J. and Abel, T. (2009) Developmental Etiology for Neuroanatomical and Cognitive Deficits in Mice Overexpressing Galphas, a G-Protein Subunit Genetically Linked to Schizophrenia. Molecular Psychiatry, 14, 398-415, 347.

[27] Koga, M., Ishiguro, H., Yazaki, S., Horiuchi, Y., Arai, M., Niizato, K., Iritani, S., Itokawa, M., Inada, T., Iwata, N., Ozaki, N., Ujike, H., Kunugi, H., Sasaki, T., Takahashi, M., Watanabe, Y., Someya, T., Kakita, A., Takahashi, H., Nawa, H., Muchardt, C., Yaniv, M. and Arinami, T. (2009) Involvement of Smarca2/Brm in the Swi/Snf Chromatin-Remodeling Complex in Schizophrenia. Human Molecular Genetics, 18, 2483-2494. https://doi.org/10.1093/hmg/ddp166

[28] Etherton, M.R., Blaiss, C.A., Powell, C.M. and Sudhof, T.C. (2009) Mouse Neurexin-1alpha Deletion Causes Correlated Electrophysiological and Behavioral Changes 
Consistent with Cognitive Impairments. Proceedings of the National Academy of Sciences of the United States of America, 106, 17998-18003.

https://doi.org/10.1073/pnas.0910297106

[29] Chen, Y.W. and Lai, W.S. (2011) Behavioral Phenotyping of V-Akt Murine Thymoma Viral Oncogene Homolog 1-Deficient Mice Reveals a Sex-Specific Prepulse Inhibition Deficit in Females That Can Be Partially Alleviated by Glycogen Synthase Kinase-3 Inhibitors but Not by Antipsychotics. Neuroscience, 174, 178-189.

https://doi.org/10.1016/j.neuroscience.2010.09.056

[30] Powell, S.B., Weber, M. and Geyer, M.A. (2012) Genetic Models of Sensorimotor Gating: Relevance to Neuropsychiatric Disorders. Current Topics in Behavioral Neurosciences, 12, 251-318. https://doi.org/10.1007/7854_2011_195

[31] Eells, J.B., Misler, J.A. and Nikodem, V.M. (2006) Early Postnatal Isolation Reduces Dopamine Levels, Elevates Dopamine Turnover and Specifically Disrupts Prepulse Inhibition in Nurr1-Null Heterozygous Mice. Neuroscience, 140, 1117-1126. https://doi.org/10.1016/j.neuroscience.2005.12.065 